evils, we still must not forget that, in morals as in science, truth is essential to safe and useful progress. It appears to me that the customary statements of total abstainers are to a large extent inaccurate, and that their arguments are in a great degree fallacious. I do not believe that inaccurate statements and fallacious arguments are weapons with which any good can be $\epsilon$ ffected, and I hope I may succeed in obtaining from others such records of their own experience as may show how far the opinions which I have ventured to express can be justified and borne out by facts. I am, Sir, your obedient servant,

Wimpole-street, October 23rd, 1877. R. BRUDENELL CARTER.

\section{FEVER IN JAMAICA.}

\section{To the Editor of THE LANCET.}

SIn,-Your paper of the 13 th inst. contains a letter from Dr. Cole on the above subject. I quite agree with him that injurious aspersions have been cast on the members of the profession practising in Jamaica. I have spent some years there, and can speak from personal experience of the ability and skill of the members of the Government medical service. The last mail brought me a letter from one of the ablest of these gentlemen, Dr. Jasper Cargill, under whose care most of the cases were, and who was the personal medical attendant of the late governor. He writes as follows:-

"I may briefly touch on the topic uppermost in the minds of all here, the deaths from yellow fever. On July 27 th I received a note from the Lieutenant-Governor requesting me to go to General Mann's mountain residence, near Newcastle, to see his stepson, Mr. Crichton, lately arrived from England. I found the young gentleman suffering from yellow fever in its worst form. Dr. Steventon met me in consultation that evening, and we both agreed that re. covery was impossible. He died on the 29 th. In the meantime Miss Rushworth, who had gone on a visit to $\mathrm{Mr}$. McDowell's at Clifton Mount, got the disease. Black vomit came on very quickly, and she died on the 30th. The Lieutenant-Governor removed to a house near Halfway Tree. On August 5th he was seized with yellow fever. I was sent for at once, and was soon after joined by Dr. Steventon. We both considered the Lieutenant-Governor a very bad subject for yellow fever, and, in addition, he was much cast down by his sudden grief. We remained with him day and night, feeding him with the greatest care, but the type of disease was as bad as it could be. Both liver and kidneys ceased to act, and he died from suppression of urine on August $9: \mathrm{h}$. General Mann was sworn in as Administrator on August 18th, and the same day he was attacked with the fever. He came at once to me for treatment. By next day Mrs. and Miss Mann were both down with yellow fever. I found that a shirt of Mr. Crichton's had been laid by in a wardrobe, and this, no doubt, was the means of infecting the family of the General. Again Dr. Steventon assisted me in consultation. After a fortnight's hard work they all recovered, which was a happy result. The nurses and servants, five in number, all got a fever of a remittent type. The Rev. Mr. Brookes, who visited the sufferers, had a mild attack of yellow fever. Mrs. Brookes, who was constantly with them, was attacked on August 2lst with a very severe form of the disease. I was with her night and day, and, I am happy to say, she recovered. While this was going on in the Hills there were a few cases of yellow fever among the merchant sailors in the hospital, but nothing worth the name of an epidemic. A few days after, the new Governor arrived, and next day his steward, a white man, was seized and died in eight hours, with a temperature of $109^{\circ} \mathrm{F}$. Dr. Steventon made a post-mortem examination, and found the stomach loaded with black vomit. This was the last case. It is easy to connect the first seven cases, beginning with Mr. Crichton, and $\epsilon$ ding with Mrs. Brookes. Mr. Crichton went to General Mann, apparently well, on the 25th July, sickened on the $26 \mathrm{th}$, and died on the $29 \mathrm{th}$. His shirt was not discovered for a week after; then it was burnt. By this time the local atmosphere was contaminated, and every person in the house was infected. I think the germ theory of disease receives some support from these cases; it seems to me that what has been discovered with regard to splenic and relapsing fevers may apply to yellow fever,
[Ocт. 27, 1877.

and, perbaps, to othertypes of fever also. I am more con. vinced than ever that the successful treatment of jellow fever depends on attacking it very early, and judicious] feeding the patient. During the febrile stage medicine may do good, but as soon as the temperature falls to $99^{\circ}$ nourishment, stimulants, and care must do the rest. In all cases of recovery the urine becomes suddenly alkaline as soon as the albumen and acidity disappear; the urine then effervesces on the addition of nitric acid. Black vomit and the fæces are both acid. Does this sudden alkalinity point out any treatment as likely to counteract this extremely acid condition of the system? A curious feature of the disease is the variation in temperature of different parts of the body, such as $106^{\circ}$ in axilla, $100^{\circ}$ in other parts, and the extremities quite cold. This is a most unfavourable symptom. Yellow fever is the most treacherous disease I know of ; it requires careful observation and much expe. rience to guide one in forming a prognosis; the changes are sudden and rapid. You can imagine what a time I have had, working day and night with much anxiety and responsibility. Dr. Steventon ably assisted me in our many consultations. The panic has now subsided, but it was carried to an absurd extent. With ali my work I managed to keep very good health."

Now, Sir, I think the above abstract amply proves that, in addition to the names mentioned in Dr. Cole's letter, Jamaica possesses another physician who is capable of treating yellow fever successfully. There has been at this time no real epidemic of jellow fever. It would appear that the violence of that disease in Jamaica is greatly less tean it was in former years long ago. During the three years I was there only two cases occurred among the troops, and both these in men much depressed by sudden grief. This agrees with Dr. Cargill's remark that the LientenantGovernor was much depressed by his grief for his lost son and daughter.

I have much pleasure in bearing testimong to the professional ability of our brethren in Jamaica.

Leamington, Oct. 15th, $18 ; 7$. I am, Sir, yours faithfully,

\section{GUNSHOT FRACTURES OF THE SKULL.}

\section{To the Editor of THE LANCET.}

SIR,-I have read carefully Dr. Oscar J. Coskerry's letter on the above subject, and fail to see that he has thrown the smallest degree of light on the interesting fact that the inner table of the skull is more splintered than the outer in ordinary depressed fractures.

I presume Dr. Coskerry has not studied Erichsen's "Surgery," or he would not say "all works on surgery" teach that this splintering depends on the greater brittleness of the inner table. In that work there are two other theories mentioned to explain the circumstance. The author's is that there is a loss of momentum in passing through the outer table; the inner table being splintered more widely than the outer one, for the same reason that the aperture of exit made by a bullet is larger than that of entry." Further on we find Mr. Teevan's explanation, which is that the aperture of entrance is cansed by the penetrating body only, whilst the aperture of exist is caused by this, plus the fragments of bone driven out of that table of the skull which was first perforated.

The explanation Dr. Coskerry advances is the absence of support on the side most splintered, which, I think, is hardly warranted by the illustration mentioned,-namely, a plate-glass window.

With all due deference to so high an authority as Mr. Erichsen, I must say I do not consider his explanation very satisfactory; because it would be easy to imagine a bullet in one case striking the inner table of the skull with an initial momentum equal to that which was lost in traversing the outer table in another case; yet the same thing would take place in both,-namely, greater splintering of the inner table.

Mr. Teevan's theory is disposed of by Mr. Erichsen when he says, "In the ordinary "punctured" fracture made, for instance, by the point of a nail being driven through the skull, it must be remembered that no fragments of the outer table or diploë are carried on wards, and that the very 